\title{
Knowledge, Attitude, and Practices of Nursing Students on Disaster Preparedness
}

\author{
Hershey Snow G. Aurelio ${ }^{1}$, Brent Jericho C. Bautista ${ }^{2}$, Rosalia M. Casimiro ${ }^{3}$, Niel Kishia R. Dichoso ${ }^{4}$, \\ Rocel A. Endaya ${ }^{5}$, Shanaia Kaye V. Ignacio ${ }^{6}$, Cheena Mallari ${ }^{7}$ \\ 1,2,3,4,5,6,7 Nueva Ecija University of Science and Technology
}

\begin{tabular}{l}
\hline \hline ARTICLE INFO \\
\hline Article history: \\
DOI: \\
10.30595/pshms.v2i.218 \\
Submitted: \\
December 6, 2021 \\
Accepted: \\
January 21, 2022 \\
Published: \\
January 26, 2022
\end{tabular}

\section{Keywords:}

Disaster Nursing, Knowledge, Attitudes, Practices, Disaster Preparedness, Nursing Students

\begin{abstract}
Nurses play a critical part in disaster response, and having nursing skills to be prepared for a disaster is essential and valuable. Healthcare workers must be explicitly trained to respond during catastrophe; thus, this study focused to determine the student nurse's knowledge, attitude, and practices on disaster preparedness as future care provider. This utilized a quantitative descriptivecorrelational approach, total enumeration sampling, and used a four-part survey questionnaire. The result showed that most respondents were female, aged 18 to 22, and a resident of rural area. Nursing students have a sufficient understanding of disaster preparedness, including the importance of effective disaster planning and preparation, disaster warnings and indicators, and the appropriate responses to consider in the event of a disaster. The nursing students have a positive attitude toward disaster preparedness, particularly regarding their families' safety. Nursing students agree that they have sufficient disaster preparedness strategies, although they are not always mentally and physically prepared when a disaster occurs. Findings revealed that students' disaster preparedness knowledge and practices significantly correlate with their demographic profile; their social integration improve as they progress through the year levels. Based on the collected data, the nursing students' knowledge, attitude, and practices are satisfactory; however, there is still potential to expand and enhance disaster preparedness knowledge, attitude, and practices. Continuing education and training workshops to become proficient in disaster preparedness could help students improve knowledge, attitude, and practices, resulting in better management and preparation for potential disaster occurrences.
\end{abstract}

This work is licensed under a Creative Commons Attribution 4.0 International License.

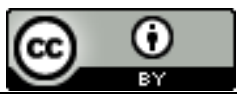

Corresponding Author:

Hershey Snow G. Aurelio,

Nueva Ecija University of Science and Technology,

Cabanatuan City, Nueva Ecija, Philippines

Email: hersheyaurelio12@gmail.com

\section{INTRODUCTION}

A disaster is a severe disruption of society that affects a vast number of people. Hospitals of all sizes and locations are affected by such an incidence. Disasters frequently strike around the world, posing severe public health risks and negatively impacting lives, infrastructure, and facilities and causing suffering and the loss of livelihoods. [1] The Philippines is particularly vulnerable to natural hazards due to the nation's geographic location in Southeast Asia. The country is plagued by natural disasters such as typhoons, earthquakes, flooding, volcanic eruptions, landslides, and fires. Volcanic eruptions and tsunamis contribute to the activity of the continental plate along the "Ring of Fire." [2]

Preparing for disaster is one way to reduce the severity of disaster impacts. Disaster Preparedness, as defined in RA 10121 by the Congress of the Philippines [3], is the knowledge and capabilities developed by governments, professional response and recovery organizations, communities, and individuals in order to 
effectively anticipate, respond to, and recover from the impacts of likely, imminent, or current hazard events or conditions.

Since catastrophes are one of the major causes of death, hospitals are the safest area for people before and after disasters since they provide essential treatment to casualties. Efficient hospital and health center management has a significant impact on the peak efficiency of these organizations. Unpredictable occurrences and multi-faceted destruction allow healthcare providers to plan and treat victims with varying degrees of competence and care to mitigate disaster effects. However, different experiences around the world, particularly in the Philippines, have revealed that uncertainty and confusion are the most typical challenges hospitals encounter when dealing with disasters. In line with this, countries were asked to respond to the World Health Organization's (WHO) call for considerable efforts to safeguard safe healthcare facilities during the disaster. [4]

Pursuant to this, nurses have a consistent presence and play a critical role in disaster response, and having nursing skills is vital and valuable for nurses in a disaster. As essential members of the healthcare team, nurses must be prepared to deal with these situations and enhance the effectiveness of the community health promotion system by gaining more expertise and understanding on how to deal with crucial problems. Nurses who have been educated and trained for disasters are expected to play a crucial role and cope better when one occurs. According to Weiner, E. healthcare professionals, particularly nurses, should be taught in disaster prevention, and contingency plans should be devised to provide faster access to services in the event of a disaster. [5]

In our environment today, it is widely accepted that disasters can occur at any time, and healthcare workers must be explicitly trained to respond to various people's needs during disasters. As a result, it is essential to understand the extent of their disaster preparedness knowledge, attitude, and practices. In line with this, future skilled nurses will be the students on disaster preparedness. The aim of the study is to assess and describe the nursing students' current knowledge, attitude, and practices on disaster preparedness. Also, this study determined the relationship between the sociodemographic data and the knowledge, attitude, and practices of nursing students on disaster preparedness that can be the basis of future protocols to be implemented by the College in collaboration with other agencies in line with disaster response.

\section{RESEARCH METHOD}

This study used a descriptive-correlational method and was conducted during the months of January-May 2021 at the College of Nursing, Nueva Ecija University of Science and Technology. This study utilized the total enumeration sampling method, and the total number of respondents is 507 nursing students. A four-part research questionnaire was used to collect data from the respondents consisting of (1) sociodemographic profile, which was described in terms of their age, sex, year level, and place of residence. (2) knowledge on disaster preparedness which was described in terms of vulnerability assessment, planning, institutional framework, information system, resource base, warning system, response mechanism, public education and training, and rehearsals (3) attitude on disaster preparedness which was described in terms of affective, behavioral, and cognitive. (4) and the practices on disaster preparedness were described in terms of mental and physical adaptive capacity, social integration, and technological integration. The questionnaire used the 5-point Likert Scale. In the validation process of this study, the researchers provided copies of the questionnaire to the faculty members expert in the field. The expert went through the research questions and the questionnaire carefully to ascertain the appropriateness and adequacy of the instrument. Also, the survey questionnaire was subjected to a reliability test through Cronbach's alpha using IBM SSPS statistics version 26. The Cronbach's alpha was used to assess the internal consistency of several items and the result was 0.92. Alpha is based on a correlation matrix and is interpreted similarly to other measures of reliability.

After the researchers collected the data through a questionnaire via google form, the researchers tabulated the findings. With the consultant statistician, the data were statistically treated. The researchers used these data for interpretation and presentation. The researchers also observed ethical considerations to such as the avoidance of error, truth, and understanding. The researchers ensure the respondent's health, safety, and anonymity. The researchers validated that the respondents do not undergo undue pressure or coercion, such as threats of penalty for failing to participate or excessive rewards for agreeing to participate in their study. Furthermore, the researchers guaranteed the safety and protection of the participants from any detrimental effects of the study. The researchers ensure the privacy and confidentiality of the respondents who answered their survey by not sharing their identity and data collected outside the group to protect the rights of the respondents. All the respondents voluntarily signed the consent form. 


\section{RESULT AND DISCUSSIONS}

\subsection{Socio-demographic Profile of the Respondents}

Table 1. Frequency distribution of age, gender, year level and place of residence of the nursing students.

\begin{tabular}{llll}
\hline & Socio-demographic profile & Frequency & Percentage \\
\hline Age & & & \\
& $18-22$ & 493 & 97.2 \\
& $23-27$ & 9 & 1.8 \\
& $28-32$ & 4 & 0.8 \\
Sex & $33-37$ & 1 & 0.2 \\
& & & \\
\multirow{2}{*}{ Year Level } & Female & 397 & 78.3 \\
& Male & 110 & 21.7 \\
& & & 25.8 \\
& 1st year & 131 & 49.9 \\
Place of Residence & 253 & 21.5 \\
& 2nd year & 109 & 2.8 \\
& 4th year & 14 & 58.6 \\
& Rural & & 41.4 \\
\hline
\end{tabular}

Based on the results, the majority of respondents are between the ages of eighteen (18) and twentytwo (22) years, accounting for 97.2 percent of the total population. It also revealed that there were more female respondents than male respondents in the study, whereas females accounted for 397 or $78.3 \%$ of the respondents. In addition, it also showed that most respondents are from the second year, with 253 respondents or $49.9 \%$ of the overall sampled population and that most of the respondents come from the rural areas, with 297 students $(58.6 \%)$.

\subsection{Knowledge on Disaster Preparedness}

Table 2. Knowledge of the Nursing Students on disaster preparedness

\begin{tabular}{lcc}
\hline \multicolumn{1}{c}{ KNOWLEDGE } & WEIGHTED MEAN & VERBAL DESCRIPTION \\
\hline Vulnerability Assessment & 4.18 & Moderately Aware \\
Planning & 4.25 & Extremely Aware \\
Institutional Framework & 4.18 & Moderately Aware \\
Information System & 3.99 & Moderately Aware \\
Resource Base & 4.12 & Moderately Aware \\
Warning System & 4.31 & Extremely Aware \\
Response Mechanism & 4.21 & Extremely Aware \\
Public Education and Training & 4.42 & Extremely Aware \\
Rehearsals & 4.36 & Extremely Aware \\
& $\mathrm{AWM}=4.22$ & Extremely Aware \\
\hline
\end{tabular}

Table 2 showed the summary of knowledge of the respondents on disaster preparedness. The table garnered an overall weighted mean of 4.22 with the verbal description of "Extremely Aware." It consists of nine (9) categories which are the Vulnerability Assessment, Planning, Institutional Framework, Information System, Resource Base, Warning System, Response Mechanism, Public Education and Training, and Rehearsals.

Table 2 also revealed that the respondents have an adequate knowledge on disaster preparedness in terms of planning, warning systems, response mechanism, public education and training, and rehearsals, and all are interpreted as "Extremely Aware". While, the Vulnerability Assessment, Institutional Framework, Information System and Resource Base, and all are interpreted as "Moderately Aware".

In terms of public education and training, the knowledge of nursing students about the importance of trainings and education for disaster preparedness, it revealed that respondents were well aware, with a weighted mean of 4.42, with a verbal interpretation of "Extremely Aware." In terms of rehearsals, the knowledge of nursing students about the benefit of participating in trainings and seminars for disaster preparedness revealed that the respondents are have an adequate knowledge also, with a weighted mean of 
4.36, with a verbal interpretation of "Extremely Aware". However, the respondents had more limited knowledge about the significance of vulnerability assessment, institutional framework, information systems, and resource base.

A sufficient quantity of qualified and competent professionals is required for effective disaster response. This can be accomplished by providing sufficient training and instruction to healthcare staff in order to instill the requisite competencies for disaster response. Knowledge, skills, abilities, and attitudes required to perform a job are referred to as competencies. [6] Also, according to Wang [7], school drills are an essential part of disaster risk reduction and school preparedness. Students are exposed to various physical dangers during an emergency and waste a considerable period at the campus. As a result, most government and school administrators conduct emergency drills and training for students and teachers to exercise and develop regular emergency management plans and risk reduction strategies.

In addition, Xue, Shu, Hayter \& Lee [8] said that the role of nursing staff in disaster rescue is receiving significant attention. Understanding the experiences of nurses during disaster response can help future leaders increase response capacity and nursing preparation through education, training, and management, as well as emotional care after a disaster occurrence. Recognizing the value of disaster nursing education and better equipping nurses to perform effectively in all phases of a disaster.

\subsection{Attitude on Disaster Preparedness}

Table 3. Attitude of the Nursing Students on disaster preparedness

\begin{tabular}{lll}
\hline ATTITUDE & WEIGHTED MEAN & VERBAL DESCRIPTION \\
\hline 1. Affective & 4.63 & Very True to Me \\
2. Behavioral & 4.38 & Very True to Me \\
3. Cognitive & 4.19 & Somewhat true to me \\
& AWM=4.40 & Very True to Me \\
\hline
\end{tabular}

Table 3 showed the summary of attitude of the respondents on disaster preparedness. The table garnered an overall weighted mean of 4.40 with the verbal description of "Very True to Me" which means that the respondents are competent with the statement. It consists of three (3) categories which are the Affective, Behavioral and Cognitive.

Table 3 also revealed that both Affective and Behavioral component are interpreted as "Very True to Me". While, the cognitive component is interpreted as "Somewhat true to me".

This means that the respondents have good feelings and positive responses regarding disaster preparedness, especially if it involves the safety of their families. In contrast, some parts of disaster preparedness make their positive perception slightly lower regarding disaster preparedness.

Family preparedness plays a crucial role in allowing nurses to respond or participate in a disaster [9]. According to the results of the study of Al Khalaileh et al., (2012), half of their respondents reported family emergency plans in place for disasters or agreements on how to execute family plans.

If nurses do not feel their families are safe or cared for, their focus and abilities to fully engage in disaster response will be affected [11]. In addition, according to [10], which state that nurses were willing to work in disaster situations when they felt their families were safe, and the family could access effective treatment options, either at the workplace or at home.

According to Nofal et al. [12], adequate earlier preparation of nurse students assists in the security and well-being of healthcare laborers and responders amid a disaster. Moreover, it may move forward the readiness of understudies to assist amid a calamity. Student nurses trained in disaster management could also be helpful in community education programs as part of a community disaster preparedness health initiative.

\subsection{Practices on Disaster Preparedness}

Table 4. Practices of Nursing Students on disaster preparedness

\begin{tabular}{lll}
\hline PRACTICES & WEIGHTED MEAN & VERBAL DESCRIPTION \\
\hline 1.Mental and Physical Adaptive Capacity & 3.67 & Agree \\
2.Social Integration & 3.77 & Agree \\
3.Technological Integration & 3.77 & Agree \\
& AWM=3.74 & Agree \\
\hline
\end{tabular}

Table 4 showed the summary of practices of the respondents on disaster preparedness. The table garnered an overall weighted mean of 3.74 with the verbal description of "Agree". It consists of four (4) 
categories which are the Mental and Physical Adaptive Capacity, Social Integration, Technological Integration.

Table 4 also revealed that the respondents agree that they have adequate practices for disaster preparedness in terms of mental and physical capacity, social integration, and technological integration.

This is the implication that although they are not always mentally and physically prepared when an actual disaster occurs, they still have enough practices for disaster preparedness due to the yearly disaster drills conducted in their school. In addition, they also agree that they have reliable practices in disaster preparedness in terms of technological integration by utilizing information and warnings found online about disaster is an effective way to become ready in case a disaster occurs.

The five studies that validated this finding emphasized the role of disaster-related training as an effective strategy for nurses to improve their disaster knowledge and skills were the studies of Abo Gad [6], Labrague et al. [13][14], Witt \& Menegat [15], Younis et al. [16].

Abo Gad [6], for example, discovered that nurses who had previously completed disaster training reported stronger personal preparation for disaster response. In a study by Labrague et al. [14], the majority of respondents said that most of their disaster management knowledge and abilities obtained from actual exercises and disaster training. These findings supported the findings of Younis et al., (2020), who found that regular disaster or emergency drills helped nurses prepare for disasters.

Nurses identified first aid training, field triage, advanced basic life support, and infection control as training needs in preparing nurses for disaster response in a different study done in the Philippines of Labrague et al. [13]. Real-time exercises, desktop exercises, pre-hospital life support, and practice drills and scenarios were also mentioned as essential experiences for nurses to fully prepare for catastrophe circumstances. [13]

\subsection{Correlation Between Profile of the Nursing Students and their Knowledge, Attitude, and Practices} on Disaster Preparedness

Table 5. Relationship between the profile of the Nursing Students and their knowledge, attitude and practices of the on disaster preparedness

\begin{tabular}{|c|c|c|c|c|c|c|c|c|c|c|c|c|}
\hline & & & VA & $\mathrm{P}$ & IF & IS & $\mathrm{RB}$ & WS & $\mathrm{RM}$ & PET & $\mathrm{R}$ & KNOWLEDGE \\
\hline \multirow[t]{3}{*}{$\overline{\text { Age }}$} & $\begin{array}{l}\text { Pearson } \\
\text { Correlation }\end{array}$ & & -.032 & -.028 & -.018 & -.059 & -.051 & -.054 & .010 & -.053 & .038 & -.033 \\
\hline & Sig. (2-tailed) & & .469 & .523 & .683 & .187 & .255 & .226 & .829 & .235 & .399 & .454 \\
\hline & $\mathrm{N}$ & & 507 & 507 & 507 & 507 & 507 & 507 & 507 & 507 & 507 & 507 \\
\hline \multirow[t]{3}{*}{ Sex } & $\begin{array}{l}\text { Pearson } \\
\text { Correlation }\end{array}$ & & -.019 & $-.089^{*}$ & * $-.125^{* *}$ & $-.102^{*}$ & $-.140^{* *}$ & $-.098^{*}$ & -.065 & -.084 & -.079 & $-.107^{*}$ \\
\hline & Sig. (2-tailed) & & .673 & .046 & .005 & .021 & .002 & .028 & .144 & .059 & .077 & .016 \\
\hline & $\mathrm{N}$ & & 507 & 507 & 507 & 507 & 507 & 507 & 507 & 507 & 507 & 507 \\
\hline \multirow[t]{3}{*}{ Year_Level } & $\begin{array}{l}\text { Pearson } \\
\text { Correlation }\end{array}$ & & -.042 & -.028 & .015 & -.021 & .017 & -.005 & -.048 & -.015 & -.013 & -.018 \\
\hline & Sig. (2-tailed) & & .342 & .522 & .742 & .631 & .708 & .915 & .284 & .734 & .765 & .679 \\
\hline & $\mathrm{N}$ & & 507 & 507 & 507 & 507 & 507 & 507 & 507 & 507 & 507 & 507 \\
\hline \multirow[t]{4}{*}{ Residence } & $\begin{array}{l}\text { Pearson } \\
\text { Correlation }\end{array}$ & & -.055 & -.049 & -.082 & -.008 & -.016 & -.063 & -.052 & -.059 & -.045 & -.056 \\
\hline & Sig. (2-tailed) & & .215 & .271 & .064 & .853 & .715 & .160 & .244 & .186 & .317 & .206 \\
\hline & $\mathrm{N}$ & & 507 & 507 & 507 & 507 & 507 & 507 & 507 & 507 & 507 & 507 \\
\hline & \multicolumn{3}{|c|}{$\mathrm{A}$} & \multicolumn{2}{|r|}{$\mathrm{B}$} & \multicolumn{2}{|r|}{$\mathrm{C}$} & \multicolumn{3}{|c|}{ ATTITUDES } & & \\
\hline \multirow[t]{3}{*}{ Age } & $\begin{array}{l}\text { Pearson } \\
\text { Correlation }\end{array}$ & \multicolumn{2}{|c|}{-.024} & \multicolumn{2}{|r|}{.003} & \multicolumn{2}{|r|}{.043} & \multicolumn{2}{|c|}{.010} & & & \\
\hline & Sig. (2-tailed) & .589 & & & .941 & & .337 & \multicolumn{2}{|c|}{.815} & & & \\
\hline & $\mathrm{N}$ & 507 & & & 507 & & 507 & \multicolumn{2}{|c|}{507} & & & \\
\hline \multirow[t]{3}{*}{ Sex } & $\begin{array}{l}\text { Pearson } \\
\text { Correlation }\end{array}$ & \multicolumn{2}{|c|}{-.082} & \multicolumn{2}{|r|}{-.062} & & -.072 & \multicolumn{2}{|c|}{-.085} & & & \\
\hline & Sig. (2-tailed) & \multicolumn{2}{|c|}{ 1) .065} & \multicolumn{2}{|r|}{.165} & & .105 & \multicolumn{2}{|c|}{.055} & & & \\
\hline & $\mathrm{N}$ & \multicolumn{2}{|l|}{507} & \multicolumn{2}{|r|}{507} & & 507 & \multicolumn{2}{|c|}{507} & & & \\
\hline \multirow[t]{2}{*}{$\begin{array}{l}\text { Year_Leve } \\
1\end{array}$} & $\begin{array}{l}\text { Pearson } \\
\text { Correlation }\end{array}$ & \multicolumn{2}{|l|}{.040} & \multicolumn{2}{|r|}{-.010} & & .081 & \multicolumn{2}{|c|}{.045} & & & \\
\hline & Sig. (2-tailed) & .375 & & & .825 & & .068 & .31 & 14 & & & \\
\hline
\end{tabular}




\begin{tabular}{|c|c|c|c|c|c|c|}
\hline \multirow{5}{*}{ Residence } & $\mathrm{N}$ & 507 & 507 & 507 & 507 & \\
\hline & $\begin{array}{l}\text { Pearson } \\
\text { Correlation }\end{array}$ & -.018 & -.025 & -.028 & -.028 & \\
\hline & Sig. (2-tailed) & .685 & .569 & .535 & .524 & \\
\hline & $\mathrm{N}$ & 507 & 507 & 507 & 507 & \\
\hline & & MPAC & SI & $\mathrm{TI}$ & & PRACTICES \\
\hline \multirow[t]{3}{*}{$\overline{\text { Age }}$} & $\begin{array}{l}\text { Pearson } \\
\text { Correlation }\end{array}$ & .026 & .044 & .012 & & .032 \\
\hline & Sig. (2-tailed) & .556 & .326 & .781 & & .478 \\
\hline & $\mathrm{N}$ & 507 & 507 & 507 & & 507 \\
\hline \multirow[t]{3}{*}{ Sex } & $\begin{array}{l}\text { Pearson } \\
\text { Correlation }\end{array}$ & .039 & -.054 & -.033 & & -.018 \\
\hline & Sig. (2-tailed) & .379 & .226 & .465 & & .687 \\
\hline & $\mathrm{N}$ & 507 & 507 & 507 & & 507 \\
\hline \multirow[t]{3}{*}{$\begin{array}{l}\text { Year_Leve } \\
1\end{array}$} & $\begin{array}{l}\text { Pearson } \\
\text { Correlation }\end{array}$ & .024 & $.137^{* *}$ & .032 & & .073 \\
\hline & Sig. (2-tailed) & .594 & .002 & .476 & & .098 \\
\hline & $\mathrm{N}$ & 507 & 507 & 507 & & 507 \\
\hline \multirow[t]{3}{*}{ Residence } & $\begin{array}{l}\text { Pearson } \\
\text { Correlation }\end{array}$ & -.060 & -.017 & .017 & & -.023 \\
\hline & Sig. (2-tailed) & .181 & .700 & .702 & & .606 \\
\hline & $\mathrm{N}$ & 507 & 507 & 507 & & 507 \\
\hline
\end{tabular}

**. Correlation is significant at the 0.01 level (2-tailed).

*. Correlation is significant at the 0.05 level (2-tailed).

The table above showed the significant relationship between the socio-demographic profile and knowledge of nursing students on disaster preparedness. Based on the results, only sex is significantly correlated with knowledge. This implies that the knowledge of females slightly tends to increase as the knowledge of males decreases in terms of planning, institutional framework, information system, resource base, and warning system. Disaster preparedness is the safest practice women can use in their personal and professional lives when disasters such as COVID-19 have become the new normal [17]. When it comes to human or natural disasters, women are particularly vulnerable, but as the situation progresses, concerns about their particular needs are either forgotten or overlooked. According to Zhaidi \& Fordham [18], when disasters strike, women are much more likely to be wounded or disabled than men when disasters occur. However, surveys on women and disasters have discovered that, while women and teenage girls are the most vulnerable in disaster scenarios, they also play a critical role in disaster risk reduction and recovery efforts [19].

In addition, the table above also showed the significant relationship between nursing students' sociodemographic profile and attitude on disaster preparedness. Based on the results, all profile variables were not significantly related to the attitude of nursing students in disaster preparedness in terms of affective, behavioral, and cognitive attitude. The Table 5 also showed the significant relationship between the sociodemographic profile and practices of nursing students on disaster preparedness Based on the results, only year level of the respondents was significantly correlated with Social Integration. This implies that the respondents' social integration tends to become higher as they level up, which supports previous studies about disaster preparedness among college students that year level affects their preparedness for disaster. Understanding how disaster-prepared college students are and what factors can improve disaster preparedness among college students is critical to improving disaster preparedness behaviors. Rising college students' emergency preparedness awareness would almost certainly result in increased disaster preparedness habits. Students who gained more emergency preparedness skills showed a higher degree of disaster preparedness. [20]

\section{CONCLUSION}

Based on the gathered data, it showed that there was a correlation between the sociodemographic profile of the nursing students and their knowledge and practices on disaster preparedness; hence the null hypothesis is rejected. The nursing students' knowledge, attitude, and practices are all at an acceptable level; however, there was still a need to improve and enhance knowledge, attitude, and practices on disaster 
preparedness. Therefore, continuous education and training workshops to become skilled for disaster preparedness could further enhance the nursing students' knowledge, attitude, and practices on disaster preparedness that could lead to better management and preparation for possible disaster emergencies.

\section{Acknowledgements}

First and foremost, praises and thanks to God, the Almighty, for His showers of blessings throughout the nursing research. The researchers would like to express their gratitude and appreciation to their family, and research adviser for giving them knowledge, wisdom, confidence, courage, guidance, and continuous support to conduct this research study.

\section{REFERENCES}

[1] G. M. Diab and S. M. Mabrouk, "The effect of guidance booklet on knowledge and attitudes of nurses regarding disaster preparedness at hospitals," J. Nurs. Educ. Pract., vol. 5, no. 9, 2015, doi: 10.5430/jnep.v5n9p17.

[2] UNDRR, "Disaster Risk Reduction in the Philippines," United Nations Off. Disaster Risk Reduct. (UNDRR), Reg. Off. Asia Pacific, 2019.

[3] Congress of the Philippines, "Ra 10121," Philippines, no. 3086, 2010.

[4] World Health Organization, Health Emergency and Disaster Risk Management: Overview. 2019.

[5] E. Weiner, "Preparing nurses internationally for emergency planning and response," Online Journal of Issues in Nursing, vol. 11, no. 3. 2006.

[6] R. Abo Gad, "Effect of Educational Program on Nurses' Knowledge and Awareness of Internal Disaster Management," Mansoura Nurs. J., vol. 1, no. 2, 2014, doi: 10.21608/mnj.2014.149022.

[7] J. J. Wang, "Study on the context of school-based disaster management," Int. J. Disaster Risk Reduct., vol. 19, 2016, doi: 10.1016/j.ijdrr.2016.08.005.

[8] C. L. Xue, Y. S. Shu, M. Hayter, and A. Lee, "Experiences of nurses involved in natural disaster relief: A meta-synthesis of qualitative literature," J. Clin. Nurs., vol. 29, no. 23-24, 2020, doi: 10.1111/jocn.15476.

[9] C. A. Brewer, A. Hutton, K. S. Hammad, and S. K. Geale, "A feasibility study on disaster preparedness in regional and rural emergency departments in New South Wales: Nurses selfassessment of knowledge, skills and preparation for disaster management," Australas. Emerg. Care, vol. 23, no. 1, 2020, doi: 10.1016/j.auec.2019.12.005.

[10] M. A. Al Khalaileh, E. Bond, and J. A. Alasad, "Jordanian nurses' perceptions of their preparedness for disaster management," Int. Emerg. Nurs., vol. 20, no. 1, 2012, doi: 10.1016/j.ienj.2011.01.001.

[11] R. L. Charney, T. Rebmann, and R. G. Flood, "Hospital Employee Willingness to Work during Earthquakes Versus Pandemics," J. Emerg. Med., vol. 49, no. 5, pp. 665-674, 2015, doi: 10.1016/j.jemermed.2015.07.030.

[12] A. Nofal, I. Alfayyad, A. Khan, Z. Al Aseri, and A. Abu-Shaheen, "Knowledge, attitudes, andpractices of emergencydepartment staff towards disaster and emergency preparedness at tertiary health care hospital in central Saudi Arabia," Saudi Med. J., vol. 39, no. 11, 2018, doi: 10.15537/smj.2018.11.23026.

[13] L. J. Labrague, B. C. Yboa, D. M. Mcenroe-Petitte, L. R. Lobrino, and M. G. B. Brennan, "Disaster Preparedness in Philippine Nurses," J. Nurs. Scholarsh., vol. 48, no. 1, 2016, doi: 10.1111/jnu.12186.

[14] L. J. Labrague et al., "Disaster preparedness among nurses: a systematic review of literature," International Nursing Review, vol. 65, no. 1. 2018, doi: 10.1111/inr.12369.

[15] R. Witt and R. Menegat, "WADEM Congress on Disaster and Emergency Medicine - 2019 Abstracts of Oral Presentations - ADDENDUM," Prehosp. Disaster Med., vol. 34, no. 4, 2019, doi: 10.1017/S1049023X19004667.

[16] N. M. Younis, M. M. Ahmed, and A. A. Hussein, "Nurses' knowledge, attitude and practice towards preparedness of disaster management in emergency of mosul teaching hospitals," Medico-Legal Updat., vol. 20, no. 3, 2020, doi: 10.37506/mlu.v20i3.1611.

[17] S. Bhadra, "Women in Disasters and Conflicts in India: Interventions in View of the Millennium Development Goals," Int. J. Disaster Risk Sci., vol. 8, no. 2, 2017, doi: 10.1007/s13753-017-0124-y.

[18] R. Z. Zaidi and M. Fordham, "The missing half of the Sendai framework: Gender and women in the implementation of global disaster risk reduction policy," Prog. Disaster Sci., vol. 10, 2021, doi: 10.1016/j.pdisas.2021.100170.

[19] K. Alam and M. H. Rahman, "Women in natural disasters: A case study from southern coastal region of Bangladesh,” Int. J. Disaster Risk Reduct., vol. 8, 2014, doi: 10.1016/j.ijdrr.2014.01.003.

[20] K. L. Goddard S, Sheppard M, Thompson K, "Disaster Preparedness Knowledge, Beliefs, RiskPerceptions, and Mitigating Factors of Disaster Preparedness Behaviors of Undergraduate Students at 
a Large Midwest University," J. Public Heal. Issues Pract., vol. 2, no. 2, 2018, doi: 10.33790/jphip1100115. 